Brit. J. industr. Med., 1951, 8, 226.

\title{
SOME OBSERVATIONS ON THE TOXIC PROPERTIES OF 3:5-DINITRO-ORTHO-CRESOL
}

\author{
BY \\ V. H. PARKER, J. M. BARNES, and F. A. DENZ \\ From the Medical Research Council Unit for Research in Toxicology, \\ Carshalton, Surrey
}

This paper records experimental work with animals on the toxicity and mode of action of dinitro-ortho-cresol (DNOC or DNC), a compound widely used in agriculture, and occasionally responsible for the death of men handling it in the field.

Most of the data on the toxicity of the related compound dinitro-phenol (DNP) was published in the decade after the 1914-18 war. During that war DNP had been manufactured in large quantities, and many cases of poisoning had occurred among the munition workers who handled it. Both DNOC and DNP were widely used for a few years as "slimming agents". A number of deaths, as well as many cases of cataract, followed the use of these drugs for this purpose. This earlier work on the toxic properties of DNP and DNOC has been fully reviewed by Magne, Mayer, and Plantefol (1932), by Tainter and Cutting (1933), and by Heymans and Casier (1935). More recently, Ambrose (1942) has published some observations on the toxicity of DNOC, including the effects of repeated injections and the cutaneous application of the drug.

In recent times the use of DNOC in agriculture has been greatly extended. Weak solutions $(0 \cdot 01 \%)$ are used as ovicides for insect pests and applied as "winter washes" to fruit trees. No casualties of any kind have been reported from among the thousands of people who have used DNOC in this way. Stronger solutions containing up to $20 \%$ DNOC have also been used as insecticides and sprayed from aircraft to destroy locusts (Gunn, 1948). Solutions of DNOC $(0 \cdot 5 \%)$ are also used as selective herbicides. Such solutions are applied in the early summer to young cereal crops to check weeds. In many cases the solutions have been applied for individual farmers by firms of contract sprayers, among the employees of these firms a number of deaths have occurred within recent years (Hunter, 1950).
The deaths amongst agricultural workers have shown that there are a number of problems to be solved. These accidental deaths often occurred with dramatic suddenness among men who had been handling the material for a considerable time. The possibility of cumulative action of DNOC, the value of estimations of blood levels of DNOC in diagnosis and prognosis, and the effect of environmental factors, such as a high external temperature, nutritional state, and alcohol consumption required investigation. In this paper these aspects of DNOC poisoning are examined. The distribution of DNOC in blood and tissues of poisoned animals was observed, and an attempt was made to explain the experimental findings in terms of modern biochemistry.

\section{Methods and Materials}

Estimation of DNOC.-Amounts of DNOC down to $2 \mu \mathrm{g}$ per $\mathrm{g}$. of tissue or $\mathrm{ml}$. of blood or urine could be recovered and estimated by a simple method of extraction in ethyl-methyl ketone and comparison with standard solutions of DNOC in the same solvent. The method is described in detail elsewhere (Parker, 1949). This method estimates both the free DNOC, and that bound to blood or tissue protein.

Certain tissues, such as the liver and kidney, contain an enzyme that will reduce DNOC so care must be taken to homogenize these tissues under conditions where this enzyme will not be active. Initially, the tissues were homogenized in dilute caustic soda, but when more was known about the properties of this enzyme, it was found that homogenization in $5 \times 10^{-3} \mathrm{M}$. cyanide was a satisfactory procedure for inhibiting the activity of the enzyme.

Detection of Products of Metabolism.-The Derrien test was performed in the way described by Magne and others (1932). Ethereal sulphates were estimated by the method of Senior (1947), and glucuronides by that of Hanson, Mills, and Williams (1944).

The animals were kept in metabolism cages, and 24-hour specimens of urine collected under toluene were used for these tests. 
Animals.-Albino rats from the Ministry of Supply Animal Farm, Porton, were used for the majority of the experiments. Albino mice, cross bred rabbits, guinea-pigs, mongrel dogs and bitches, and a few cats were also used.

DNOC.-This was purified by recrystallization from $50 \%$ alcohol. It was administered as a $1 \%$ solution in weak sodium carbonate solution adjusted to $p \mathrm{H} 7$ with hydrochloric acid.

The solution was given in the majority of cases by subcutaneous injection. The drug is very rapidly absorbed and the solutions do not irritate the tissues.

When administered in feeding experiments, measured quantities of a dilute DNOC solution were mixed with weighed quantities of a powdered rat diet to give a known final concentration of DNOC intimately mixed with the food. The daily intake was calculated from the known average intake of food by the rat.

Histology.-Tissues were fixed in formol saline and Helly's solution and prepared in the usual way. Haematoxylin and eosin and certain special stains for glycogen and mitochondria were used.

\section{Results}

Lethal Dose and Signs of Acute Poisoning.-The average lethal dose of DNOC administered by subcutaneous injection in a single dose was very much the same for rats, mice, rabbits, guinea-pigs, and dogs. The L.D.50 was calculated for rats and mice and found to be 24.6 (fiducial limits-23.1 $-26 \cdot 1$ ) and $24 \cdot 2$ (fiducial limits - 21.5-27.3) $\mathrm{mg}$. DNOC per $\mathrm{kg}$. respectively.

After injection of $20 \mathrm{mg}$. per $\mathrm{kg}$., rats behave normally for 10 to 15 minutes. The rate of respiration then begins to increase rapidly, and within the next 15 minutes the animal is lying prostrate on its belly. It usually lies quite still except for an occasional fine convulsive movement. This condition persists for one to two hours with a gradual recovery. Within four hours the animals are again active, and by 18 hours appear perfectly normal. If food is left in their cage they eat voraciously as soon as they have recovered sufficiently to move about. However, over a 24-hour period their food consumption is not measurably greater than that of normal rats.

Where the dose of DNOC proves fatal, the respiration rate continues to increase after the animal has become prostrate. Death may be preceded by a few convulsive gasps, or it may take place quietly with nothing but a slight outstretching of the limbs to mark it. As a rule muscular rigidity develops just before death, and is complete when the animal dies. This muscular rigidity is a very striking feature and persists for some hours after death. A few observations were made on changes in rectal temperature in poisoned rats.
The changes were very irregular, but death can occur in the absence of any hyperpyrexia.

Death usually takes place within two hours of the administration of doses around the L.D.50. Observations on 109 rats that died after a single injection of 20 to $25 \mathrm{mg}$. DNOC per $\mathrm{kg}$. showed that $76 \%$ were dead within two hours, and $91 \%$ within five hours. Deaths delayed for 18 hours or more were never observed.

Mice, rabbits, and dogs react in a way very similar to that of the rats except that dogs usually vomit within two hours of receiving a toxic dose. Delayed deaths were not seen in these species.

Effects of Repeated Doses.-The effects of a single dose of DNOC clearly were shortlived, and the animal either died within a few hours or recovered completely. This has an important bearing on the problem of the possible cumulative effects of DNOC. This problem was investigated by giving rats a series of daily doses of $20 \mathrm{mg}$. DNOC per $\mathrm{kg}$. for periods extending up to six weeks. In the earlier experiments, the injected rats were kept in the warm laboratory. Under these conditions it was found that 5 to $15 \%$ died shortly after the injection on any of the first four days, but thereafter only a very occasional acute death was noted even though the injections were continued for three weeks. In later experiments, it was found that significantly fewer rats died if their cages were placed in a cool draughty corridor immediately they had received the DNOC. The figures for these and the earlier experiments (Table 1) show that when the doses are given at successive intervals of 24 hours there is no evidence of cumulative action as judged by the death rate following the injections.

If, however, the interval between consecutive doses is shortened, a cumulative action for DNOC can be demonstrated in both rats and rabbits. A single dose of $5 \mathrm{mg}$. per $\mathrm{kg}$. of DNOC produces no visible signs of poisoning, but when hourly injections are given characteristic signs of poisoning appear after the fourth or fifth injection. At first, symptoms are shortlived and disappear before the next injection is due. Later they last longer, and the animal dies shortly after an injection. Death takes place in both rats and rabbits after the total dose administered amounts to 25 to $35 \mathrm{mg}$. per $\mathrm{kg}$. This is the size of a lethal dose when given as a single injection. The similarity of behaviour in this respect in these two species is of interest because, as will be shown later, the rate of disappearance of DNOC from the blood stream is different.

As rats can survive a long series of injections of $20 \mathrm{mg}$. per $\mathrm{kg}$. of DNOC daily as recorded above and in Table 1, and as almost all the deaths occur 
TABLE 1

INCIDENCE OF DEATH AMONG RATS RECEIVING DAILY DOSES OF 20 MG. PER KG. DNOC

\begin{tabular}{|c|c|c|c|c|c|c|c|}
\hline \multirow[b]{2}{*}{ Experiment } & \multirow{2}{*}{$\begin{array}{l}\text { No. of } \\
\text { Injections }\end{array}$} & \multirow{2}{*}{$\begin{array}{l}\text { No. of } \\
\text { Rats }\end{array}$} & \multicolumn{2}{|c|}{ Deaths } & \multirow{2}{*}{\multicolumn{3}{|c|}{$\begin{array}{c}\text { Day of Deaths (No. of Animals } \\
\text { in Brackets) }\end{array}$}} \\
\hline & & & Total & Per- & & & \\
\hline 1. Rats in warm* laboratory & 17 & 87 & 27 & 31 & 1st (10) & 2nd (4) & 3rd (11) 4th (2) \\
\hline 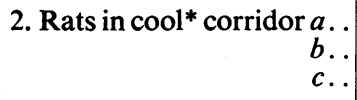 & $\begin{array}{c}10 \\
20 \\
36-45\end{array}$ & $\begin{array}{r}110 \\
62 \\
23\end{array}$ & $\begin{array}{l}4 \\
4 \\
2\end{array}$ & $\begin{array}{l}3 \cdot 6 \\
6 \cdot 5 \\
8 \cdot 5\end{array}$ & $\begin{array}{l}\text { 2nd (2) } \\
\text { 4th (3) } \\
\text { 4th (1) }\end{array}$ & $\begin{array}{l}5 \text { th (1) } \\
5 \text { th (1) } \\
21 \text { st (1) }\end{array}$ & 7 th (1) \\
\hline $\begin{array}{l}\text { * Difference between ““ } \\
\text { Difference between “" } \\
\text { Difference between “ }\end{array}$ & $m ",(1)$ & ol & & & ant & $\begin{array}{l}\chi^{2}=27 \cdot 48 \\
\chi^{2}=13 \cdot 23 \\
\chi^{2}=4 \cdot 69\end{array}$ & $\begin{array}{l}\mathrm{P}<0.001 \\
\mathrm{P}<0.001 \\
\mathrm{P}=0.03\end{array}$ \\
\hline
\end{tabular}

after the first few injections, the possibility arises that tolerance to DNOC can be developed. This question was examined by taking the survivors of the series of injections of $20 \mathrm{mg}$. per $\mathrm{kg}$. and giving them a single dose of $30 \mathrm{mg}$. per $\mathrm{kg}$. The mortality rate of these animals was found to be lower than that of a control group given the single injection of $30 \mathrm{mg}$. per $\mathrm{kg}$. This could be taken as evidence of the development of tolerance, but there is the alternative explanation that the previous injections weeded out the susceptible rats and left a selected group of resistant rats. Further, the fact that symptoms of poisoning following the injection of a dose of $20 \mathrm{mg}$. per $\mathrm{kg}$. DNOC show no appreciable amelioration at the end of a long series of injections points to the absence of any tolerance in animals exposed to repeated doses.

In spite of the severe symptoms of poisoning produced each day by a series of such injections, the rats show no evidence of any serious constitutional disturbance. On an unrestricted diet, rats submitted to such treatment with DNOC do not invariably lose weight, and may have ample amounts of adipose tissue after 45 successive injections of $20 \mathrm{mg}$. per kg. per day.

Dogs given daily doses of 5 and $10 \mathrm{mg}$. per $\mathrm{kg}$. for 12 successive days showed no evidence of cumulative poisoning.

When DNOC was administered in the diet of rats, cumulative poisoning was only observed when the calculated daily intake of the drug greatly exceeded the single lethal dose.

At a level of 200 parts per million of DNOC in the diet giving a calculated intake of $15 \mathrm{mg}$. per kg. per day, rats grew normally over an observed period of 18 weeks. When the calculated dose was $30 \mathrm{mg}$. per $\mathrm{kg}$. per day no symptoms appeared in rats eating this diet for two and a half weeks, but within four days of doubling the quantity in the food the rats became obviously ill, and four out of 12 rats were dead within 10 days.
Pathological Changes.-Tissues from 78 rats have been examined by both routine and special histological methods. Material was obtained from rats dying after a single large dose, and from animals killed or dying after a series of injections.

Kidney.-The presence of protein in the glomerular filtrate was a constant feature where rats died after a dose of 25 to $30 \mathrm{mg}$. per $\mathrm{kg}$. Animals killed or dying after smaller doses never showed this protein. The same changes were found in rats dying of overheating and it may therefore be the result of hyperpyrexia.

Liver.-No sign of cellular damage has been found in the livers of rats killed or dying after either single or repeated injections of DNOC. In animals killed up to 48 hours after the last of a series of injections, the lobular pattern of the liver was lost. The parenchymal cells were swollen and packed together. Special staining showed them to be filled with glycogen. When the rat died of acute poisoning, the findings were variable; of 18 livers from such animals, eight had little or no glycogen, while 10 showed increased storage of glycogen. There was no increased storage of glycogen in the tubules of the kidney, in the adipose tissue or in heart muscle. The mitochondria of the liver cells, stained by Altmann's method, were apparently normal, but when the cells were packed with glycogen, the mitochondria were distributed round the periphery and round the nucleus.

Lungs.-When animals died after DNOC or were killed when showing symptoms, there was an intense pulmonary congestion and slight pulmonary oedema.

Adipose Tissue.-In two special experiments the adipose tissue of the testicular omentum and interscapular pad (brown fat) were examined. No histological changes could be detected in the fatty tissue even after a series of 15 daily injections.

The spleen, thymus, thyroid, cardiac and voluntary muscle showed no consistent or unusual variation from the normal. 


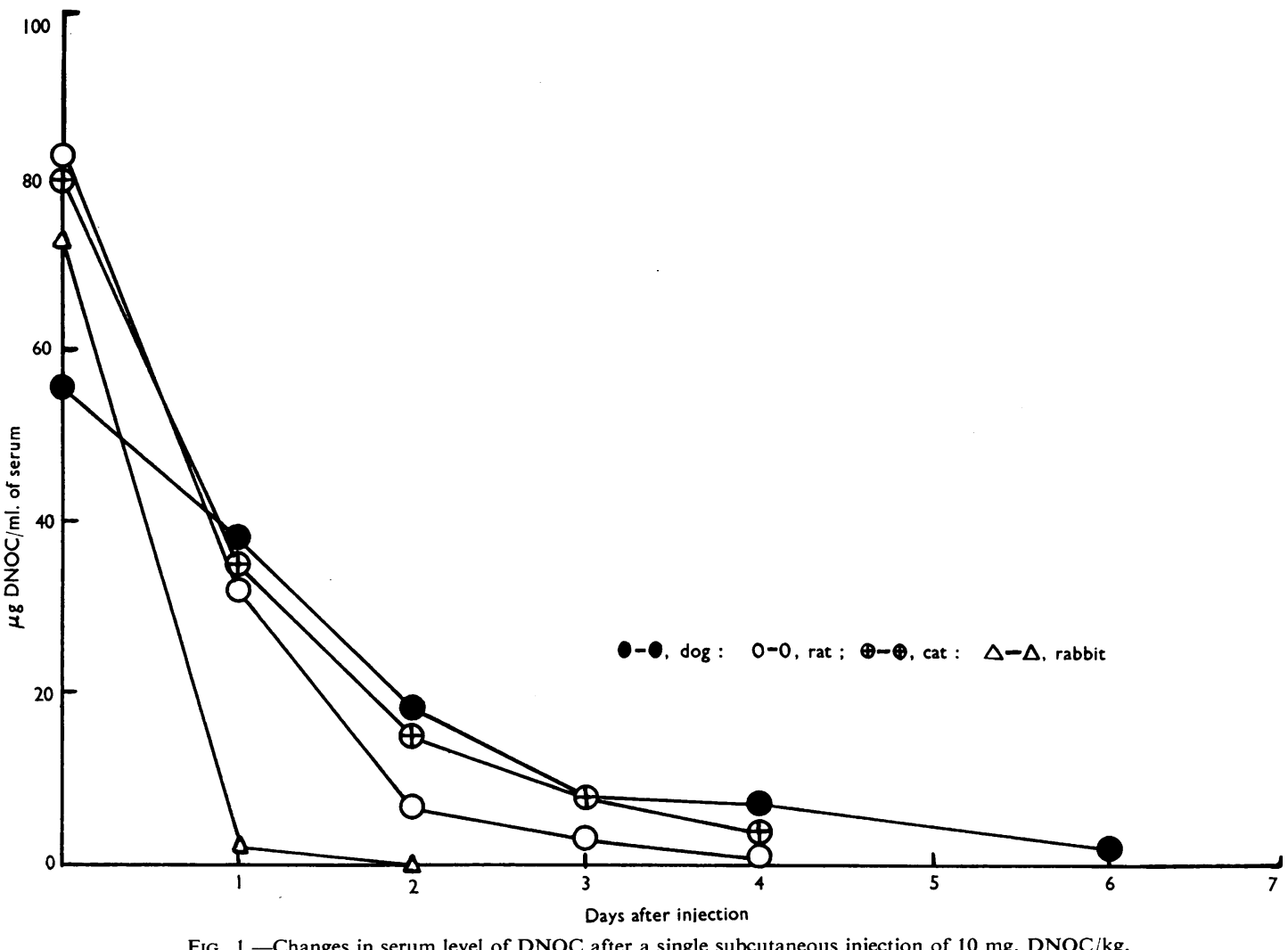

Fate of Injected DNOC. - The existence of a simple and accurate method for estimating small quantities of DNOC in the tissues and body fluids enabled the distribution of DNOC after its subcutaneous injection to be studied.

Blood Levels. - The blood level of DNOC was determined in rabbits, rats, cats, and dogs after the subcutaneous injection of DNOC. Over $90 \%$ of the DNOC was in the plasma, and only small quantities were found in the red blood cells. It was possible to take serial samples from the larger species, but as a minimum of $2 \mathrm{ml}$. of blood was required, a rat had to be sacrificed to obtain enough blood for each determination. The figures for blood levels in rats were obtained by taking the mean value for the blood samples from a group of four rats which had been similarly treated, and had been killed at the same time.

Curves showing the changes in blood level after a single injection of DNOC given to rats, rabbits, dog, and cat are given in Fig. 1. The curves are exponential in character. The rate of fall in the blood level of DNOC differs in the various species. The time taken for the DNOC level in the blood to fall to half its initial value after a single injection of $10 \mathrm{mg}$. DNOC per $\mathrm{kg}$. is in the rabbit about three hours, in the rat 15 hours, in the cat 20 hours, and in the dog 36 hours.

It will be seen in Fig. 1 that after 24 hours the blood level in the rabbit is virtually zero. If the rabbit is given a series of injections on successive days, the rate of fall in the blood level of DNOC remains unchanged on each successive day (Fig. 2). In the rat, the rate of fall after a single injection is slower and as much as $30 \mu \mathrm{g}$ per ml. of DNOC remains in the blood 24 hours later. Despite this residue in the blood it is not possible to produce a progressive rise in the blood level by giving a series of injections at 24-hour intervals. If the rats are given a second injection 24 hours after the first injection of DNOC, the blood level still falls to the same level 24 hours after the second dose as it did after the first dose. The dog behaves in the same way as the rat, and when given a series of daily injections of $10 \mathrm{mg}$. per $\mathrm{kg}$. on five successive days, the blood level 24 hours after each injection did not fluctuate significantly.

Furthermore, it was found that after the administration of DNOC had stopped, the rate of disappearance of DNOC from the blood of the dog was exactly the same whether the animal had received one or a number of daily injections beforehand 


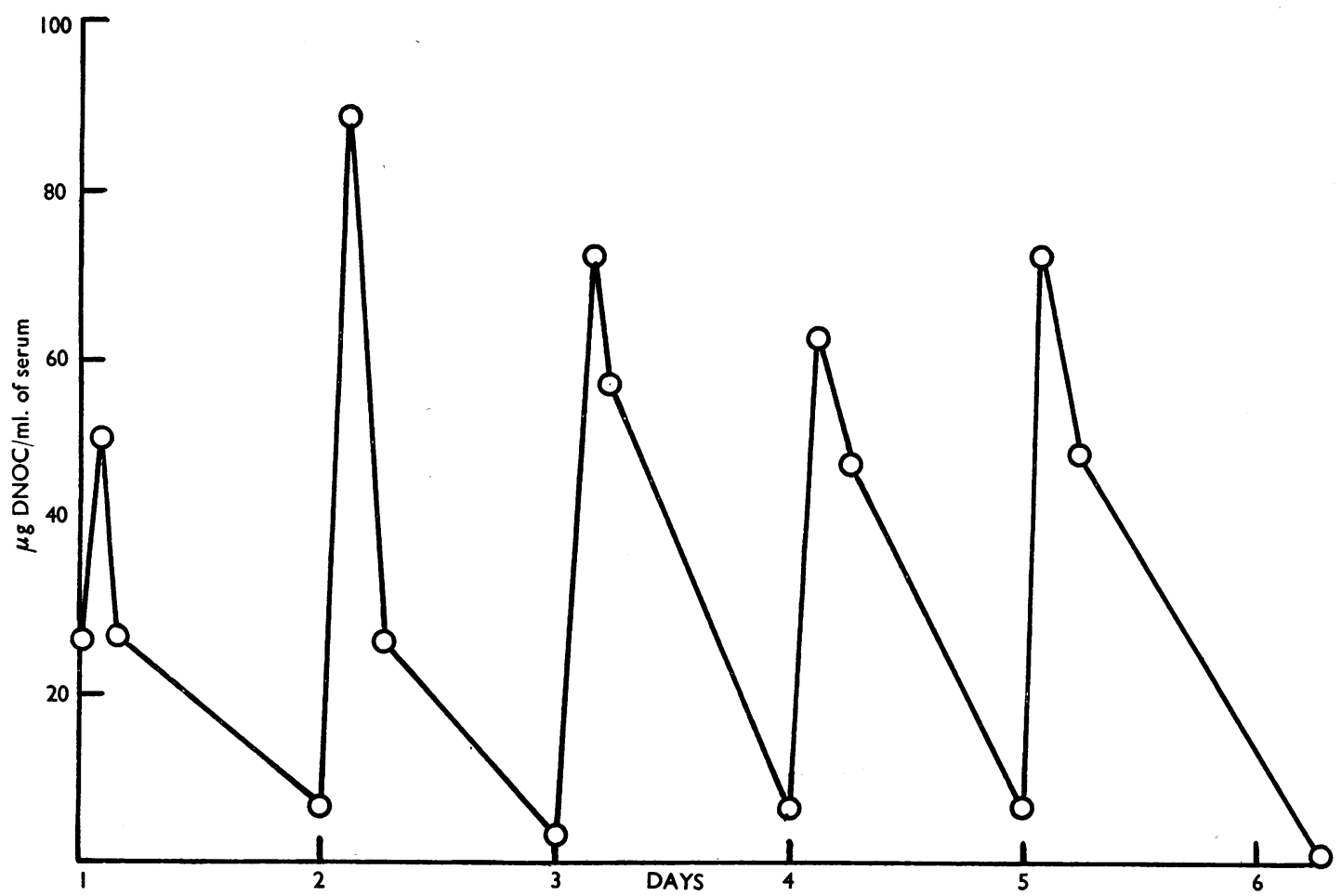

FIG. 2.-Effect of repeated subcutaneous injections $(10 \mathrm{mg}$. DNOC/kg.) on serum level of DNOC in rabbit. Samples of serum analyzed immediately after injection and then at one, three, five, and 24 hours.

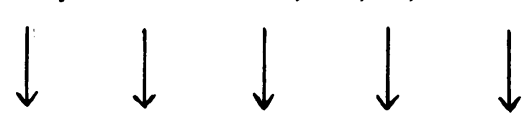

$=$ Injection of $10 \mathrm{mg}$. DNOC per Kilo

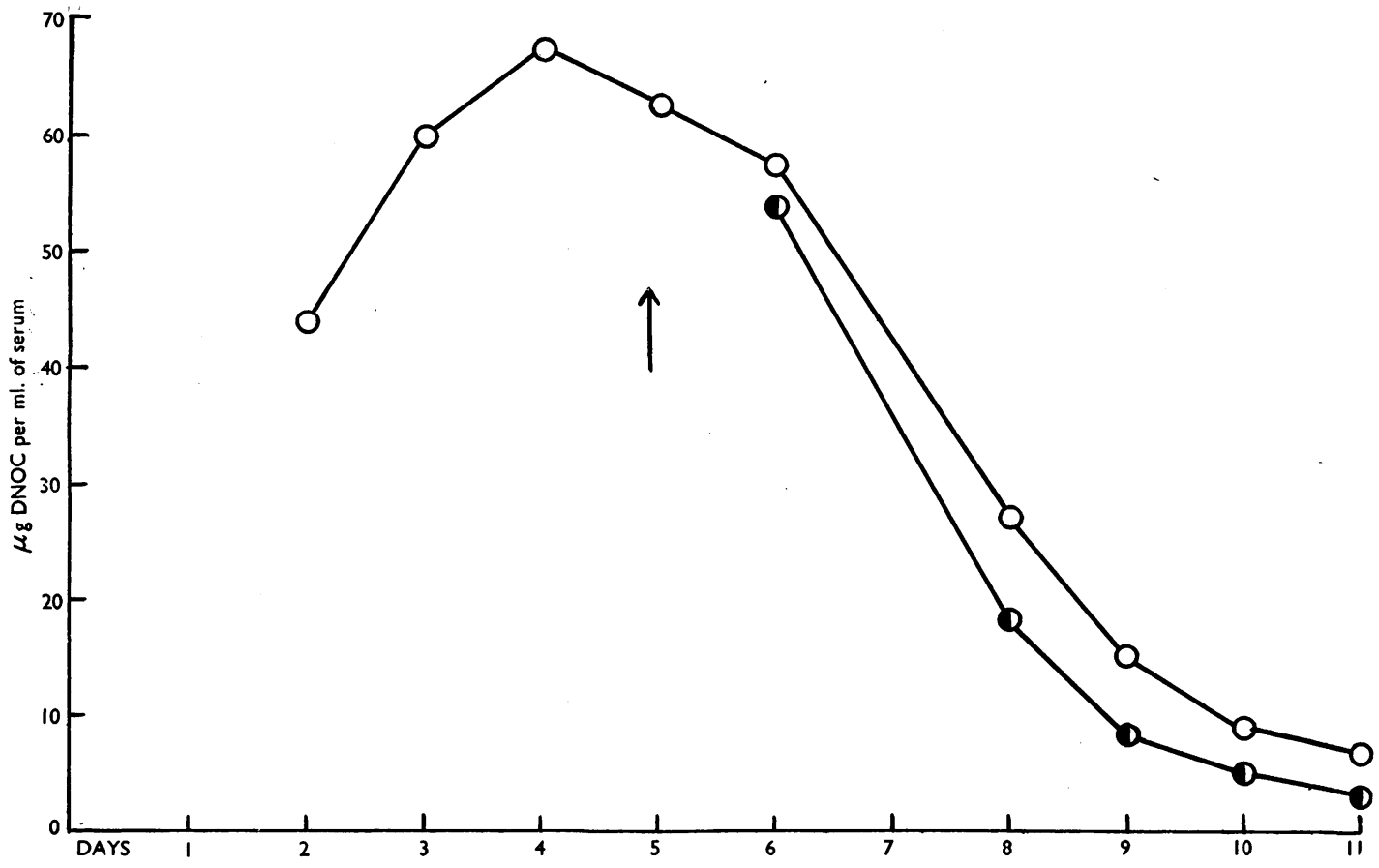

Fig. 3.-The upper curve shows the effect of five daily subcutaneous injections on the DNOC concentration in serum of dog (serum samples taken 24 hours after the previous injection). After the fifth day, no further injections were given.

The lower curve shows the rate of fall of DNOC in serum following a single injection 24 hours before the first sample was taken. 
(Fig. 3). The rat behaves in a similar way (see below and Table 3 ). There is no evidence of an accumulation of DNOC in the blood of dogs, rats and rabbits receiving a series of daily injections of DNOC.

The persistence of a certain amount of DNOC in the circulating blood, 24 hours or more after the last injection of the drug in the dog and the rat, does not reflect any greater susceptibility of these species to further injections. DNOC is cleared much more rapidly from the blood of the rabbit than from the rat. But if rats and rabbits are given hourly injections of DNOC in doses of $5 \mathrm{mg}$. per kg. they both behave similarly. The same total dose, 25 to $35 \mathrm{mg}$. per $\mathrm{kg}$., is lethal to each species and they die with blood levels of approximately the same height (125 $\mu \mathrm{g}$ per $\mathrm{ml}$.).

One explanation of the persistence of an appreciable part of the injected DNOC in the blood of the dog and rat for some days, is that this DNOC is fixed to the circulating plasma protein, and that it is only slowly released from this attachment. DNOC will readily attach itself to serum proteins in vitro. But there is no evidence from in vitro experiments that the plasma protein of the rabbit was less efficient in binding DNOC than the rat. Thus, at a concentration of $100 \mu \mathrm{g}$ DNOC per ml. in $5 \mathrm{ml}$., $1 \mathrm{ml}$. of rabbit serum adsorbed $65 \%$ of the DNOC whereas $1 \mathrm{ml}$. of rat serum only adsorbed $48 \%$. The explanation of the more rapid disappearance of the DNOC from the blood of the rabbit must be independent of the power of the plasma protein to bind DNOC.

Distribution of DNOC in the Tissues.-Rats were given a subcutaneous injection of $10 \mathrm{mg}$. per $\mathrm{kg}$. and killed by guillotine at intervals afterwards. The amount of DNOC present in the serum and in the brain, spleen, kidney, liver, muscle, heart, and lung was determined. The results are given in Table 2.

It will be seen that the concentration of DNOC in the serum is outstandingly high by comparison with that in other tissues. The high figures for the DNOC content of the lungs and heart may have been due to their relatively high blood content in relation to the weight of the whole organ. The heart was removed in toto, and dropped into the tube for homogenization without any preliminary washing to free its cavities from blood. It will be seen that there was no evidence of the accumulation of DNOC in any particular tissue.

From a knowledge of the weights of the different tissues and organs, and assuming the blood to be $6 \%$ of the body weight, it was possible to calculate that within 30 minutes of the injection of $1.5 \mathrm{mg}$. DNOC, $0.725 \mathrm{mg}$. could be recovered from the animal, and $83 \%$ of this was in the blood. After six hours $0.37 \mathrm{mg}$. could still be accounted for, and at least $72 \%$ of this was in the blood. By this time all the acute symptoms of poisoning had disappeared.

The DNOC content of the liver and kidneys of rats was also determined in animals that had received a long series of daily injections of $20 \mathrm{mg}$. DNOC per $\mathrm{kg}$. The figures are given in Table 3, and show that the concentration of DNOC in the blood, liver and kidneys, 24 hours after the last injection of a dose of $20 \mathrm{mg}$. per $\mathrm{kg}$. DNOC was the same in animals receiving a single injection as in those that had received 40 successive daily injections.

In other animals the levels in the liver, kidney, and blood were compared 24 and 48 hours after the last injection of DNOC, and again there was no difference in the rates at which the animals could rid their tissues of DNOC whether they had received one or 40 successive injections. There was thus no evidence of accumulation of DNOC in the tissues or, after long exposure to DNOC, of any alteration in the rate at which the animal metabolised DNOC.

Excretion.-The excretion of DNOC in the urine of rabbits and dogs that had received either single or multiple injections of DNOC was studied. The total quantity of DNOC administered ranged from 0.5 to $80 \mathrm{mg}$. The urine was collected during the days the injections were given, and for the three days succeeding the last injection. Between four and $10 \%$ of the total DNOC injected was recovered from the urine as DNOC. There was no significant difference between the amounts recovered from the dogs and from rabbits despite the more rapid fall in the blood level that is observed in the rabbit.

In no case was a positive Derrien test obtained on the urine of either the dog or rabbit. This test is thought to show the excretion of amino-nitrophenol, a conjectural metabolite of DNOC. Tests for glucuronides were negative. The estimations for ethereal sulphates showed there was no significant increase in the amounts excreted by the animals that had been injected with DNOC. These estimations were done to examine the possibility that DNOC or a breakdown product might be excreted in a form combined with glucuronic acid or as an ethereal sulphate. There is no evidence of this.

Factors Affecting the Susceptibility of Rats to DNOC.-Male and female rats whether young or old are equally susceptible to a single toxic dose of DNOC. So also are well-fed rats with continued 
TABLE 2

DNOC CONTENT* OF BLOOD AND TISSUES OF RATS KILLED AT INTERVALS AFTER SUBCUTANEOUS INJECTION OF ONE DOSE OF 1.5 MG. DNOC

\begin{tabular}{lll|c|c|c|c|c|c|c|c}
\hline \multicolumn{2}{c|}{ Time after Injection } & Serum & Brain & Spleen & Kidney & Liver & Muscle & Heart & Lung \\
\hline 30 mins. &.. &.. & 100 & 1.5 & 4.0 & 7.5 & 14.0 & 0.5 & 8.0 & 18.0 \\
1 hr. &.. &. & 89 & 3.5 & 4.0 & 7.5 & 12.0 & 2.0 & 13.5 & 20.0 \\
2 hrs. &.. &.. & 97 & 2.0 & 4.5 & 11.0 & 10.5 & 0.0 & 19.0 & 20.5 \\
3 hrs. &.. &.. & 93 & 4.0 & 8.0 & 11.0 & 11.5 & 3.5 & 14.0 & 15.5 \\
4 hrs. &.. &. & 79 & 3.5 & 3.0 & 4.5 & 13.5 & 0.5 & 13.0 & 14.0 \\
5 hrs. &.. &.. & 76 & 2.0 & 4.0 & 4.5 & 8.5 & 2.0 & 14.0 & 14.5 \\
6 hrs. &.. &. & 45 & 3.0 & 1.5 & 7.5 & 8.5 & 1.5 & 10.5 & 30.0 \\
\hline
\end{tabular}

* DNOC content of tissue $=\mu \mathrm{g} . /$ lg. wet weight.

TABLE 3

COMPARISON OF DNOC CONCENTRATION IN SERUM, KIDNEY, AND LIVER OF RATS AFTER SINGLE AND 40 SUCCESSIVE DAILY INJECTIONS EACH OF 20 MG. DNOC PER KG.

\begin{tabular}{|c|c|c|c|c|c|c|c|}
\hline \multirow{2}{*}{\multicolumn{4}{|c|}{ Treatment }} & \multirow{2}{*}{$\begin{array}{l}\text { No. of } \\
\text { Rats }\end{array}$} & \multicolumn{3}{|c|}{$\begin{array}{c}\text { Concentration of DNOC } 24 \text { Hours after Last } \\
\text { Injection }(\mu \mathrm{g} / \mathrm{g} \text {. wet wt.) }\end{array}$} \\
\hline & & & & & Liver & Kidney & Serum \\
\hline $\begin{array}{l}\text { a. One injection } \\
\text { b. } 40 \text { daily injections }\end{array}$ & $\begin{array}{l}\cdots \\
\cdots\end{array}$ & $\begin{array}{l}\cdots \\
\cdots\end{array}$ & $\begin{array}{l}\cdots \\
\cdots\end{array}$ & $\begin{array}{l}19 \\
9\end{array}$ & $\begin{array}{l}8 \pm 0.7 \mu g^{*} \\
7 \pm 0.3 \mu g\end{array}$ & $\begin{array}{l}7 \pm 0.2 \mu \mathrm{g} \\
7 \pm 0.3 \mu \mathrm{g}\end{array}$ & $\begin{array}{l}45 \pm 1.6 \mu \mathrm{g} \\
38 \pm 1.0 \mu \mathrm{g}\end{array}$ \\
\hline
\end{tabular}

* Results expressed as means and standard errors.

access to food, and under-fed rats when the dose of DNOC given was adjusted to their body weight.

Alcohol was given to rats as a $10 \%$ solution as their sole source of fluid for three days before and immediately after the injection of $20 \mathrm{mg}$. per $\mathrm{kg}$. DNOC. The toxic action and rate of recovery from the effects of the DNOC were not affected. Rejsek (1947) has stated that in man, alcohol may cause a recrudescence of the symptoms of poisoning after meta-dinitrobenzene. Although dinitrobenzene does not resemble DNOC in its mode of action, it was thought possible that alcohol may affect adversely poisoning with aromatic nitro-derivatives, in general. An experiment similar to that Rejsek was tried with rats that had received a toxic dose of DNOC. The rats were given $5 \mathrm{ml}$. of $6 \%$ alcohol by stomach tube one, two, and three days after the injection of DNOC. No symptoms other than those attributable to the alcohol were observed.

The effects of heat and cold were also examined. Tainter (1934) claimed that animals kept in the cold were less susceptible to the action of DNP. When the dose of DNOC just borders on the lethal dose this effect of cold is readily observed. As recorded above, it was found that deaths among groups of rats receiving a series of daily injections of $20 \mathrm{mg}$. per $\mathrm{kg}$. DNOC were reduced from $31 \%$ in rats kept in a warm laboratory (Table 1) to between 8.5 and $3.6 \%$ when the animals were placed in a cool, draughty corridor.

The effects of greater extremes of heat and cold were also investigated. Rats were injected with various doses of DNOC and then placed in warm or cold rooms for the next four hours. Normal rats kept under the same conditions were not killed. The results are presented in Table 4. The figures show that susceptibility was increased significantly when the animals were kept at 36 to $37^{\circ} \mathrm{C}$. A significant degree of protection from the effects of larger doses was produced when the animals were kept at 5 to $10^{\circ} \mathrm{C}$.

\section{Discussion}

The observations reported in this paper have been made for the most part on animals receiving a lethal or near-lethal dose of DNOC. These doses rapidly produce a severe disturbance of the general metabolism which either proves fatal or else it is completely reversed within a few hours. Such a syndrome of acute poisoning can be produced 
TABLE 4

EFFECT OF ENVIRONMENTAL TEMPERATURE ON SENSITIVITY OF RATS TO SINGLE DOSE OF DNOC

\begin{tabular}{|c|c|c|c|c|c|c|}
\hline \multirow{3}{*}{$\begin{array}{l}\text { Dose of DNOC } \\
\quad(\mathrm{mg} . / \mathrm{kg} .)\end{array}$} & \multicolumn{6}{|c|}{ Environment } \\
\hline & \multicolumn{2}{|c|}{ Cold $5-10^{\circ} \mathrm{C}$} & \multicolumn{2}{|c|}{ Room Temperature $18-20^{\circ} \mathrm{C}$} & \multicolumn{2}{|c|}{ Warm $36-37^{\circ} \mathrm{C}$} \\
\hline & $\begin{array}{l}\text { No. of } \\
\text { Rats }\end{array}$ & $\begin{array}{c}\text { Mortality } \\
(\%)\end{array}$ & $\begin{array}{l}\text { No. of } \\
\text { Rats }\end{array}$ & $\begin{array}{c}\text { Mortality } \\
(\%)\end{array}$ & $\begin{array}{l}\text { No. of } \\
\text { Rats }\end{array}$ & $\begin{array}{c}\text { Mortality } \\
(\%)\end{array}$ \\
\hline 15 & 一 & - & 28 & 0 & 18 & 6 \\
\hline 20 & 27 & 0 & 88 & 5 & 43 & 60 \\
\hline 25 & 30 & 23 & 18 & 39 & - & - \\
\hline 30 & 18 & 72 & 32 & 97 & - & - \\
\hline
\end{tabular}

Rats were maintained in the hot or cold rooms for four hours after the injection of the DNOC. Deaths all occurred within this four hour period.

Doses corresponding to $50 \%$ mortality by converting the mortalities into probits (and using the maximum likelihood solution) are :-

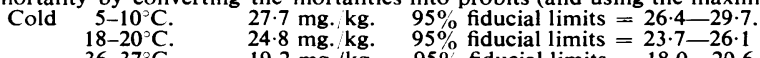
$36-37^{\circ} \mathrm{C}$. $\quad 19.2 \mathrm{mg} . / \mathrm{kg} . \quad 95 \%$ fiducial limits $=18.0-20.6$

day after day for five to six weeks in rats without leading to either cumulative poisoning or the development of any tolerance towards the drug. No histological changes indicative of structural damage to vital organs can be observed. The changes in cardiac and voluntary muscle recently described by Hicks (1950) occur with equal frequency in normal animals.

An increase in the respiratory rate is a constant feature of poisoning by DNOC, and this persists even while the animal is prostrate. Complete prostration was seen constantly in animals injected with a dose of $20 \mathrm{mg}$. per $\mathrm{kg}$. DNOC, and in these animals only the respiratory muscles and the heart were apparently capable of functioning at the time when poisoning was most severe. Hyperpyrexia is an incidental, but by no means an essential, feature of intoxication by DNOC in rats. Death, when it occurs, appears to result from an acute failure of muscular activity. The animals become prostrate, with rapid, panting respiration. If they are observed carefully it will be found that the skeletal muscles become stiff just before the animal dies. Respiratory and cardiac activity cease simultaneously, and at the moment of death muscular rigidity is complete. An explanation of this sequence of muscular paralysis followed by rigidity can be sought in the recent biochemical studies of the action of DNOC. It has long been recognized that a characteristic action of DNOC on living cells is to increase the intake of oxygen, and this has been found not only in all mammals and birds, but also in preparations as diverse as mitochondria (Loomis and Lipmann, 1948) ; tissue slices (Alwall, 1936) ; sea urchin eggs (Crane and Keltch, 1949); and bees (Goble and Patton, 1946). Loomis and Lipmann (1948) threw new light on the problem when they discovered that preparations of kidney mitochondria treated with dinitrophenol (a compound of similar properties to DNOC) took up more oxygen, but failed to combine in the usual way with the phosphate present in the suspending fluid. These observations were extended by Judah and Williams-Ashman (1951), who found that mitochondria poisoned with DNP required increasing amounts of carbohydrate to form organic phosphate esters from inorganic phosphate and that the formation of phosphate esters continuously fell.

A tentative synthesis of these facts can now be made. The oxidation of carbohydrate forms the main source of energy of the body and the energy is tapped off in the form of compounds containing phosphate, e.g. the " high energy phosphate bonds" of adenosine triphosphate (A.T.P.). This compound is then a source of available energy to the body. If DNOC poisoning in the whole animal follows a similar pattern, the formation of adenosine triphosphate would be inhibited. The oxidative processes continue and indeed speed up, but the energy cannot be converted in the body into a useful form, and so it is dissipated as heat. This would account for any rise in body temperature that took place. In the muscle the initial source of energy is believed by many to be the energy-rich phosphate bonds of A.T.P. If the A.T.P. cannot be resynthesised and is progressively broken down to adenylic acid the muscle then goes into rigor. A very similar result was produced first by Lundsgaard (1930) with iodoacetic acid. This compound acts by inhibiting the enzyme triosephosphate dehydrogenase and this also results in the progressive breakdown of A.T.P. and death of the muscle in rigor. 
The suggested mode of action of DNOC is consistent with the acute form of poisoning that is observed, but it would form a less satisfactory explanation for any chronic effects on metabolism if these were found. The only evidence of any cumulative effect of DNOC is the slight amount of DNOC that persists for some days in the serum of the rat and the dog. In the dog this may be as high as $60 \mu \mathrm{g}$ per ml. 24 hours after the injection of $10 \mathrm{mg}$. DNOC per $\mathrm{kg}$. and its presence does not appear to disturb the dog in any way. It can be calculated that $60 \mu \mathrm{g}$. per $\mathrm{ml}$. is three times the concentration that will completely inhibit phosphorylation in mitochondrial preparations but this comparison is a highly artificial and deceptive one.

However, Dr. J. D. Judah (personal communication) has shown that the DNOC in dog serum (at a level of $60 \mu \mathrm{g}$ per ml.) is still active against mitochondrial preparations, and behaves just as an aqueous solution of DNOC would behave. The naked mitochondria used by biochemists are much more vulnerable than the mitochondria in the cell protected by at least two semipermeable membranes from toxic substances in the blood, and it is probable that considerable extra-cellular concentrations are necessary in order to get any transport of the drug into the cell. The DNOC circulating in the blood of the dog is at least, in part, bound to protein and it is possible that this bound DNOC may not readily pass through all membranes.

The rapid recovery from the effects of DNOC, and the fact that cumulative poisoning does not occur unless the consecutive doses are given within a few hours of each other, suggests that the animal is able to get rid of DNOC rapidly. Only a very small part of the injected DNOC is excreted in the urine, and the conclusion can be drawn that the DNOC must be converted in the body into some inactive material. It is known that the reduction of one of the two nitro groups of DNOC will result in a compound devoid of all the metabolic stimulating properties of DNOC. Homogenized preparations of the liver and kidney will reduce DNOC in vitro (Parker, to be published). When an animal has been killed with DNOC, the compound disappears rapidly from the liver after death, but much more slowly from the blood. It is possible that some of the DNOC is reduced in the tissues where it actually exerts its effect upon metabolism, and this is probably the large muscle mass of the body which is so profoundly affected in DNOC poisoning.

Chronic poisoning by DNOC has not been observed in experimental animals, although in the dog, cat, and rat appreciable quantities of DNOC may persist in the blood for several days after a single sublethal dose. These animals do not seem to be any more susceptible to DNOC when the interval between injections is 24 hours. As many as 40 consecutive doses have been administered and under these conditions there is no progressive accumulation of DNOC in the blood. If the doses are spaced closely enough, as with hourly injections, the effects of small doses can be cumulative. The statement that DNOC has no chronic effects is therefore relative, and is used in the usual sense of effects produced days or weeks after the original exposure.

The relevance of these findings to DNOC poisoning in man is difficult to assess. The symptoms of acute poisoning in animals closely resemble those reported in man, and the muscular rigidity that comes on immediately after death in animals has been found in human fatalities (Malter, 1949). The question whether in man the toxic effects of one day's absorption of DNOC can be carried over to the next day cannot be answered by animal experiments, although these suggest that this chronic effect is unlikely. The need for information on the blood level of DNOC in man in the days following the absorption of a non-fatal dose is obvious, but the interpretation of such blood levels may be difficult. Animal experiments have shown that the persistence of DNOC in the blood at levels up to $45 \mu \mathrm{g}$ per $\mathrm{ml}$. of serum does not appear to increase the susceptibility of the animal to a further sublethal dose. It is apparent that the relation between blood levels of DNOC and symptoms in man may not be simple, and that caution must be observed before any particular blood level is adopted as dangerous or critical.

\section{Summary}

The toxic reactions of animals to injections of DNOC are described. A single dose approximating to a lethal dose produces an acute reaction lasting a few hours.

The same dose may be administered at daily intervals for several weeks without producing symptoms or signs of chronic poisoning. Administered at intervals of 24 hours, DNOC shows no cumulative effects nor do rats develop any tolerance towards it.

The blood and tissue levels of DNOC have been examined in rats and the blood levels in rats, rabbits, dogs, and cats after an injection of DNOC.

The effect of alcohol and environmental temperature on the susceptibility of rats have been examined. Small changes of environmental temperature may affect the mortality from a dose of DNOC that is just not lethal at ordinary room temperatures. 
The findings are discussed in relation to the behaviour of DNOC in tissues in vitro.

We are grateful to Dr. J. O. Irwin of the Statistical Research Unit (M.R.C.) for the figures for the probit analysis given in Table 4.

\section{RfFERENCES}

Alwall, N. (1936). Skand. Arch. Physiol., 72, Suppl.

Ambrose, A. M. (1942). J. Pharmacol., 76, 245.

Crane, R. K., and Keltch, A. K. (1949). J. gen. Physiol., 32, 503.

Goble, G. J., and Patton, R. L. (1946). J. econ. Ent., 39, 177.

Gunn, D. L. (1948). Nature, Lond., 161, 342.
Hanson, S. W. F., Mills, G. T., and Williams, R. T. (1944). Biochem. $J ., 38,274$.

Heymans, C., and Casier, H. (1935). Arch. intern. Pharmacodyn., $50,20$.

Hicks, S. P. (1950). Arch. Path., 50, 545.

Hunter, D. (1950). Brit. med. J., 1, 506.

Judah, J. D., and Williams-Ashman, H. G. (1951). Biochem. J., 48, 33 .

Loomis, W. F., and Lipmann, F. (1948), J. biol. Chem., 173, 807.

Lundsgaard, E. (1930). Biochem. Z., 217, 162.

Malter, A. (1949). Arch. belges. Méd. soc., 7, 475. Magne, H., Mayer, A., and Plantefol, L. (1932). Ann. Physiol.

Parker, V. (1949). Analyst., 74, 646.

Rejsek, K. (1947). Acta. med. scand., 127, 179.

Senior, N. (1947). Quart. J. Pharm., 20, 507.

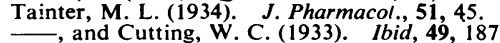

